\title{
El reconocimiento constitucional de la objeción de conciencia ${ }^{1}$
}

The constitutional recognition of conscientious objection

O reconhecimento constitucional da objeção de consciência

La reconnaissance constitutionnelle de l'objection de conscience

\section{Mariano Manuel Bär ${ }^{2}$ Universidad Católica de Santa Fe}

Revista Derechos en Acción / ISSN 2525-1678 / e-ISSN 2525-1686

Año 4/NNo 10 Verano 2018/2019 (21 diciembre a 21 marzo), 280-306

DOI: https://doi.org/10.24215/25251678e254

ORCID: https://orcid.org/0000-0002-6262-5159

Recibido: 10/02/2019

Aprobado: 10/03/2019

Resumen: La objeción de conciencia es considerada un derecho humano y es uno de los grandes temas jurídicos del Estado democrático del siglo XXI. Su importancia está dada en razón de que en las últimas décadas ha habido una extensión significativa de este instituto jurídico, abarcando ámbitos donde tradicionalmente no se había manifestado. Si bien no se encuentra expresamente regulada en el ordenamiento constitucional argentino y no se ha desarrollado una doctrina autónoma, su reconocimiento por parte de la Corte Suprema de Justicia de la Nación

1 Este trabajo se realizó en el marco de la asignatura "Derecho Constitucional y Derechos Humanos" de la Maestría en Derecho Público de la Universidad Nacional de Rosario (Santa Fe, Argentina).

2 Abogado por la Facultad de Derecho y Ciencia Política de la Universidad Católica de Santa Fe; Director del Área de Acciones de Clase de la Fundación Derecho Social (FDS); Miembro del Instituto de Derecho Constitucional del Colegio de Abogados de Santa Fe (1era Circunscripción); Miembro Adherente de la Asociación Argentina de Derecho Constitucional (AADC).bar.mariano@gmail.com 
como derivado de otros derechos fundamentales permite delinear caracteres generales para la profundización de su estudio.

Palabras clave: objeción de conciencia; libertad de conciencia; libertad de religión; libertad de pensamiento.

Abstract: Conscientious objection is considered a human right and is one of the great legal issues of the democratic State of the 21 st century. Its importance is given because in the last decades there has been a significant extension of this legal institute, covering areas where it had not traditionally been manifested. Although it is not expressly regulated in the Argentine constitutional order and an autonomous doctrine has not been developed, its recognition by the Supreme Court of Justice of the Nation as a derivative of other fundamental rights allows delineating general characteristics for the deepening of its study.

Key words: conscientious objection; freedom of conscience; freedom of religion; freedom of thought.

Resumo: A objeção de consciência é considerada um direito humano e é uma das grandes questões jurídicas do Estado democrático do século XXI. Sua importância é dada em razão de que nas últimas décadas, tem havido uma extensão significativa desse instituto jurídico, abarcando áreas onde tradicionalmente não se havia manifestado. Embora não se encontra expressamente regulada na ordem constitucional argentino e não foi desenvolvida uma doutrina autônoma, seu reconhecimento pela Corte Suprema de Justiça da Nação como derivado de outros direitos fundamentais permite delinear características gerais para o aprofundamento de seu estudo.

Palavras-chave: objeção de consciência; liberdade de consciência; liberdade de religião; liberdade de pensamento.

Résumé: L'objection de conscience est considérée comme un Droit Humain, et elle est aussi l'une des grandes questions juridiques de l'État démocratique du XXle siècle. Sa relevance este donnée par sa significative extension dans les dernières décennies, dans lesquelles elle a couvert des zones où traditionnellement elle ne s'était pas manifestée. Bien qu'elle ne soit pas expressément réglementée par l'ordre constitutionnel argentin, et qu'aucune doctrine autonome n'ait été élaborée en la matière, sa reconnaissance par la Cour Suprême de Justice de la Nation 
en tant que dérivé d'autres droits fondamentaux, permet de définir des caractéristiques générales pour approfondir son étude.

Mot-clés: Objection de Conscience; liberté de conscience; Liberté de religion; Liberté d'opinion

\section{Introducción}

La objeción de conciencia es uno de los grandes temas jurídicos del Siglo XXI. Como lo sostiene Marcelo Alegre (2009) "si durante siglos la objeción de conciencia estuvo centrada en quienes, por razones religiosas o éticas, se negaban a sumarse a las filas militares (...) lo que se observa en las últimas décadas es una extensión significativa del uso de este concepto" (p. 1).

Hoy en día, nadie en el mundo jurídico niega el carácter de derecho fundamental de la objeción de conciencia. Sin embargo, su reconocimiento no ha sido autónomo, expreso y con carácter general - si esto fuera posible-, sino que ha sido tratado como un derecho contenido dentro de la libertad de pensamiento, de conciencia, de culto, en un juego interpretativo armónico y complementario con la autonomía personal. La excepción está dada en ámbitos específicos de aplicación como la prestación del servicio militar, donde los instrumentos internacionales y las legislaciones internas de los Estados - al menos muchas de ellas - expresamente se refieren a la objeción de conciencia como causal de justificación del incumplimiento del deber legalmente impuesto. En nuestro medio, además, algunas aristas de la objeción de conciencia se encuentran legisladas en el ámbito sanitario, como la de los profesionales sanitarios a través de la Ley $\mathrm{N}^{\circ} 26.130$, que establece el Régimen para las Intervenciones de Contracepción Quirúrgica; o en cuanto a la posibilidad de rechazo de tratamientos médicos en la Ley $\mathrm{N}^{\circ}$ 26.529, denominada de derechos del paciente.

Las libertades de pensamiento, conciencia y religiosa, han sido reconocidas en la Declaración Universal de los Derechos 
Humanos y, con términos semejantes, en el Pacto Internacional de Derechos Civiles y Políticos y en la Convención Americana sobre Derechos Humanos. Instrumentos internacionales que, por lo demás, en nuestro medio jurídico gozan de jerarquía constitucional y forman parte del denominado bloque de constitucionalidad federal, en virtud del artículo 75 inciso 22 de la Constitución Nacional.

En orden al derecho interno, la Constitución Nacional reconoce la libertad de cultos en su artículo 14, siendo este, en la actualidad, más amplio que la libertad religiosa. Sobre este punto, Hernán Gullco (2016) afirma que desde el caso "Portillo" -que va a ser analizado oportunamente- la Corte Suprema de Justicia de la Nación "resolvió que el concepto de libertad 'religiosa' también abarcaba a las conductas derivadas de motivos éticos, morales o filosóficos" (p. 70), expandiendo fuertemente su ámbito de tutela constitucional.

Por su parte, son pocas las sentencias donde la Corte Suprema de Justicia de la Nación se ha expedido en torno a la objeción de conciencia — como el mencionado caso "Porti1lo"- La mayoría de las veces en las que se han presentado casos susceptibles de ser resueltos a través de la apelación al instituto de la objeción de conciencia, el tribunal ha optado por resolverlos a través de la referencia otros derechos.

En este sentido, al realizar un análisis crítico del encuadre jurídico que la Corte Suprema de Justicia de la Nación le diera al caso "Barrios", Carlos Santiago Nino (1983) advirtió el desconocimiento del tribunal en torno a

La grave cuestión de filosofía política que está latente en esta clase de casos, concentrándose, en cambio, en cuestiones importantes pero menos controvertibles, como es la del ejercicio del derecho de aprender; de este modo los tribunales, como lo señaló Francisco M. Bosch, habían desperdiciado la oportunidad de sentar pautas orientadoras en materias que reciben el embate de concepciones contrapuestas de moralidad social (Citado en Gullco, 2016, p. 96). 
Como consecuencia de ello, la jurisprudencia de la Corte Suprema de Justicia de la Nación en la materia específica de la objeción de conciencia es escasa. Esto no nos permite sostener que exista, al menos en nuestro país, una doctrina de la objeción de conciencia que precise sus alcances y límites, ni que determine estándares de interpretación generales. Mucho menos nos permite extraer estándares que la aborden como un derecho autónomo, distinto de la libertad de pensamiento, de conciencia, de culto y de la autonomía personal, si esto fuera posible.

Más allá de lo dicho, y por lo pronto, creo que la escasez de jurisprudencia no impide que puedan esbozarse algunos primeros lineamientos que sirvan de base para la construcción de una doctrina autónoma de la objeción de conciencia como derecho fundamental, y ese es el objetivo del presente trabajo.

\section{Un marco teórico para el análisis: la teoría de la justicia de Rawls}

Para fundamentar y justificar el derecho a la objeción de conciencia, desde la perspectiva de la filosofía jurídica pueden tomarse distintos autores de frontera, entendiendo por tales a aquellos que han estudiado la figura en el desarrollo de sus tesis fundamentales y a los que los demás autores acuden recurrentemente para desarrollar sus propias teorías. Como afirma Sarlo (2006) el criterio de saturación nos va a indicar que es el momento de suspender la revisión bibliográfica y comenzar el estudio de la misma cuando los conceptos, clasificaciones y conceptualizaciones empiezan a arrojar los mismos resultados.

En este sentido, quizás sean Rawls, Dworkin y Habermas a quienes con mayor frecuencia se recurre. En nuestro caso, entendiendo que su teoría es la más clara con relación al tema abordado, tomaremos el desarrollo que ha hecho John Rawls en su "Teoría de la Justicia".

Este autor define a la objeción de conciencia como un acto que

Consiste en no consentir un mandato legislativo más o menos directo, o una orden administrativa. Es objeción ya 
que es una orden que se nos dirige a nosotros, y dada la naturaleza de la situación, su aceptación por nuestra parte es conocida por las autoridades. (Rawls, 2012, p. 335).

Sus motivaciones pueden no necesariamente ser políticas, lo que distingue a la objeción de conciencia de la desobediencia civil, ni van a implicar una apelación a principios de justicia de la mayoría, sino que "puede fundarse en principios religiosos o de otra clase, en desacuerdo con el orden constitucional" (Rawls, 2012, p. 336).

Ahora bien, para comprender la teoría rawlsiana, primero hay que dejar en claro que en su "Teoría de la Justicia", el filósofo estadounidense analiza el problema de la desobediencia civil que se desarrolla en un tipo específico de sociedad. Lo advierte al señalar que "el problema de la desobediencia civil, tal y como lo interpretaré, solo se produce en un Estado democrático más o menos justo para aquellos ciudadanos que reconocen y aceptan la legitimidad de la Constitución" (Rawls, 20012, p. 331).

Así, en este tipo de sociedad el problema de la desobediencia civil se va a presentar en el campo del deber. Es decir, en los conflictos que se originan cuando la obligación de cumplir la ley va a enfrentarse a un deber de oposición a la injusticia.

El problema que el desobediente va a enfrentar, al igual que en otros autores, como Dworkin, es de carácter moral, ya que como miembro de una sociedad está obligado a cumplir con las leyes, pero también en la obligación moral de evitar la injusticia.

En punto a distinguir a la desobediencia civil y la objeción de conciencia, como ya fue dicho, la obra de Rawls resulta un poco más clarificadora que el resto y, en efecto, muchas de las demás teorías que abordan la problemática de la desobediencia civil y la objeción de conciencia son simples pretensiones de corrección sobre ella.

En este sentido, tanto la desobediencia civil como la objeción de conciencia son modalidades de desobediencia al derecho. Sin embargo, ambas se diferencian de otras desobediencias que tienen su origen en motivos morales y políticos. 
Rawls en su desarrollo distingue tres tipos de desobediencias: la desobediencia revolucionaria, la desobediencia civil, y la objeción de conciencia.

La desobediencia revolucionaria va a pretender cambiar completamente el gobierno o la carta política de una sociedad, en tanto que la desobediencia civil va a tratar de frustrar una normatividad jurídica o una decisión gubernativa. Por su parte, la objeción de conciencia será una violación del derecho en virtud de que al agente le está moralmente prohibido obedecerlo, ya sea en razón de su carácter general o porque se extiende a ciertos casos que no debieran ser cubiertos por él (Rawls, 2012).

En cuanto a los caracteres distintivos de cada una, la desobediencia civil supone un acto público, no violento, contrario a la ley, que tiene la esperanza de un cambio que se propone en esa ley o ese programa político. En cambio, la objeción de conciencia es un acto privado, consciente, que rehúsa cumplir un precepto legal, que no abriga esperanza alguna de cambio y que se apoya en principios morales, políticos, religiosos o filosóficos de acuerdo al orden constitucional. Es un acto privado hecho para proteger al agente de interferencias por parte de la autoridad pública.

Ahora bien, el concepto de desobediencia de Rawls es restrictivo no sólo porque su análisis se produce en una sociedad democrática más o menos justa, sino también porque exige que el desobediente acepte o comparta los principios de justicia de su comunidad que, circunstancialmente, se ven vulnerados por la mayoría. En este sentido, la desobediencia civil no apela a principios de moralidad personal o doctrinas religiosas, sino que invoca la concepción de justicia comúnmente compartida, que subyace bajo el orden político, es decir, que es un acto dirigido y justificado por principios políticos.

Por su parte, la objeción de conciencia se presenta cuando una persona, en el ejercicio de un derecho, se niega a cumplir pacíficamente un precepto jurídico cuya observancia le prohíbe su íntimo convencimiento. Quien se erige como objetor, a 
diferencia del desobediente, no va a apelar necesariamente a las reglas de justicia de su comunidad (principios políticos), sino que puede rehusarse a la realización de un deber jurídico porque sencillamente es contrario a su conciencia. Pero también

Puede basarse, sin embargo, en principios políticos. Podemos negarnos a consentir una ley suponiendo que es tan injusta que el obedecerla está fuera de toda duda. Este sería el caso, si la ley ordenase que fuésemos el agente que somete a un destino similar. Éstas serían patentes violaciones de los principios políticos reconocidos (Rawls, 2012, pp. 336-337).

Con buen criterio señala Marina Gascón Abellán (1990) que, en Rawls, no se adivinan tanto las conductas diferentes entre el desobediente y el objetor, sino más bien motivaciones y, acaso, diferentes modos de exteriorización. Agregando que, tal vez, un segundo elemento distintivo radique en el carácter de la norma incumplida que, en el caso del desobediente, podrá ser cualquiera y que, en el caso del objetor, debe ser aquella que le provoca el rechazo moral.

En cuanto a la justificación de la objeción de conciencia, Rawls no la aborda de manera particular, sino que se limita a desarrollar la justificación de la desobediencia civil. Sin embargo, en tanto la objeción de conciencia se define y justifica en contraste de la desobediencia civil, necesariamente debemos realizar, en este punto, un estudio conjunto de ambas.

La "Teoría de la Justicia" justifica a la desobediencia civil en tanto reúna una serie de requisitos, y ellos son: a) que la insumisión al derecho descanse en alguno de los principios de justicia de un Estado democrático y, concretamente, en el principio de igualdad de oportunidades o el de libertad igual; b) que la desobediencia se formule como último recurso, agotando previamente las vías jurídicas o institucionales para reparar la injusticia o modificar el criterio de gobierno; c) se debe evitar que las concretas circunstancias de la insumisión provoquen graves desórdenes que podrían destruir la eficacia 
de la Constitución; y d) los desobedientes deberán cuidar que su acción esté planificada de manera que sea correctamente interpretada por la comunidad.

Pareciera que, por el desarrollo de la objeción de conciencia que hemos realizado en los párrafos anteriores, ninguno de los requisitos enunciados la alcanzan en cuanto a su justificación.

Puntualmente, cuando Rawls habla de la justificación de la objeción de conciencia, lo hace exclusivamente en relación al supuesto del servicio militar y de una objeción basada en principios políticos. Por eso, sostiene Gascón Abellán (1990), y coincidimos, que ello

Lógicamente le conduce a reflexionar, más que sobre la justificación general de esta forma de insumisión, sobre las condiciones que en un Estado justo debe reunir el reclutamiento, la iniciativa y la conducción de la guerra (...) lo que aquí interesa es que, tras justificar algunos casos de objeción a la luz de principios políticos, manifiesta su rechazo a cualquier otra objeción que invoque principios distintos. (...) Si he entendido bien, ello significa que Rawls admite la hipótesis de una objeción de conciencia ética o religiosa ajena a los valores que presiden el sistema constitucional, pero que, en el fondo, sólo considera justificada aquella que pueda invocar en su favor los principios políticos de justicia. (pp. 207-208).

Este será, en términos generales, mi enfoque teórico al momento de realizar el análisis de la jurisprudencia de la Corte Suprema de Justicia de la Nación en materia de objeción de conciencia y, desde luego, desde donde se tratará de arribar a las conclusiones del presente trabajo.

\section{Reconocimiento constitucional y convencional de la objeción de conciencia}

Como fue dicho, la objeción de conciencia no encuentra un reconocimiento expreso en nuestra Constitución Nacional. Tampoco encuentra reconocimiento expreso, salvo en los supuestos de servicio militar, en los instrumentos internacionales de 
derechos humanos que, junto con la Constitución Nacional, forman el bloque de constitucionalidad federal, ostentando supremacía en el ordenamiento jurídico argentino.

En efecto, como fue adelantado en la introducción a este trabajo, su reconocimiento ha sido un producto derivado del desarrollo de otros derechos: la libertad pensamiento, la libertad de conciencia, la libertad de culto y la libertad autonomía personal en su esfera de protección de la intervención estatal, que es, la protección de la autonomía de la persona. Por lo tanto, el reconocimiento deriva, en nuestro medio, de los artículos 14 y 19 de la Constitución Nacional.

Puntualmente, fue en el fallo "Portillo" (CSJN, 1989, Fallos 312:496) donde la Corte Suprema de Justicia de la Nación por primera vez reconoció el carácter constitucional de la objeción de conciencia - como derivada de la libertad de cultos, pero también de la autonomía personal, estableciendo un ámbito protegido para la conciencia del ciudadano-, advirtiendo que la tensión entre el derecho de rehusarse a prestar el servicio militar obligatorio por razones de conciencia y la obligación de armarse en defensa de la Patria y de la Constitución, reconocen su fuente en disposiciones constitucionales que no resultan incompatibles y cuya reglamentación debe ser razonable.

Dicho que el reconocimiento de la objeción de conciencia proviene, hasta el momento, del reconocimiento de la libertad de pensamiento, de conciencia, de culto y de la autonomía personal, creo necesario distinguir el contenido de cada uno de estos derechos.

Previo a ello, importa delimitar y referenciar las conductas de las personas según éstas sean privadas o públicas. A mí entender, respecto de las consecuencias jurídicas que de las conductas emanan, es posible distinguir en las personas entre acciones privadas internas, acciones privadas externas y acciones públicas.

Las acciones privadas internas son aquellas que son incognoscibles para terceros, íntimas o inmanentes a la persona que 
las realiza, y que comienzan y concluyen en ella. Dentro de estas acciones podemos encontrar conductas inmateriales, como el pensamiento, o acciones que se materializan y exteriorizan al mundo, pero que continúan siendo inasibles para los demás.

Las acciones privadas externas, en cambio, son aquellas que aún materializadas y exteriorizadas al mundo, y conocidas por terceros, no interesan al orden público, ni afectan el bien común, ni perjudican a terceros.

La tutela del artículo 19 de la Constitución Nacional, en tanto se refiere a que "Las acciones privadas de los hombres que de ningún modo ofendan al orden y a la moral pública, ni perjudiquen a un tercero, están sólo reservadas a Dios, y exentas de la autoridad de los magistrados", es comprensiva tanto de las acciones privadas internas como externas. A su vez, no puede el Estado imponer la obligación de realizar alguna de estas conductas.

Por su parte, las acciones públicas son también externas. Trascienden a su ejecutor y se caracterizan por preocupar al orden público y al bien común. Dentro de estas conductas, según puedan comprometer al orden público y al bien común, serán prohibidas o permitidas por el Estado. Además, en este caso, incluso puede el Estado obligar a realizar determinadas conductas.

Realizada la distinción de conductas posibles, y retomando la delimitación conceptual de la libertad de pensamiento, de conciencia y de culto, destaco junto con Arletazz (2012), que existen dos posiciones teóricas relevantes al respecto,

Para una corriente más tradicional, la libertad de conciencia sería una faceta de las libertades religiosas, que incluirían a aquélla junto con la libertad de culto. La libertad de conciencia (también llamada libertad de creencias) sería el derecho de la persona a formarse sus ideas respecto de un orden trascendente y sobrenatural en general; en tanto que la libertad de culto incluiría el derecho a manifestar exteriormente esas ideas mediante los ritos y las conductas exigidas por las propias convicciones. La 
libertad de pensamiento, en cambio, comprendería la posibilidad de formarse ideas y creencias respecto de los diversos aspectos de la vida, no necesariamente limitado al ámbito de lo trascendente-religioso, como en el caso anterior. La libertad de conciencia sería un derivado del derecho a la intimidad, una cuestión de volición interna, en tanto que la libertad de culto implicaría el aspecto externo de ese derecho (la manifestación pública del culto que se ha elegido).

Desde una visión más amplia (y contemporánea) la libertad de conciencia implica una modalidad de autodeterminación en toda creencia, tomando el concepto de creencia en un sentido valorativo. La libertad de pensamiento es entonces entendida como la libertad propiamente ideológica (libertad de visión del mundo y del ser humano en relación a él). La libertad de pensamiento está vinculada con las ideas; la libertad de conciencia, con la posibilidad de darse patrones valorativos para dirigir la propia vida. Para algunos, la libertad de pensamiento es el género que involucra la libertad de conciencia; para otros, la relación es inversa. En cualquier caso, cuando las creencias referidas por la libertad de conciencia sean creencias religiosas, estaremos en el ámbito de la libertad religiosa (pp. 347-348).

La segunda visión, más amplia y contemporánea, es la que considero atinada en tanto permite la tutela diferencial de cada una de las libertades examinadas de manera autónoma.

Ahora bien, profundizando un poco más el contenido de cada una de ellas, la libertad de pensamiento se refiere a una conducta privada interna de la persona. Desde la visión más tradicional, el pensamiento es la acción y el efecto de pensar, y pensar es discurrir, reflexionar, por lo que mientras no se manifieste, no es posible que se conozca y, por lo tanto, es ajeno a toda consideración jurídica. Por lo tanto lo que el derecho protege no es el pensamiento en sí mismo sino su exteriorización (Rosatti, 2017). Así también es entendido en la Convención Americana sobre Derechos Humanos, que en su artículo 13.1 reconoce que "Toda persona tiene derecho a la libertad de pensamiento y de 
expresión", y cuyos alcances fueron establecidos a través de la Corte Interamericana de Derechos Humanos con su Opinión Consultiva OC-5/85, sobre colegiación obligatoria de periodistas, solicitada por el Gobierno de Costa Rica. En definitiva, el pensamiento constituiría una conducta privada interna y la tutela correspondería únicamente cuando el pensamiento trasciende al individuo a través de su expresión. Lo propio ocurre con el artículo 18 de la Declaración Universal de Derechos Humanos donde "Toda persona tiene derecho a la libertad de pensamiento" y, en los mismos términos y con el mismo texto, el artículo 18.1 del Pacto Internacional de Derechos Civiles y Políticos.

La otra posibilidad, que comparto, es entender que la libertad o derecho de pensamiento, en palabras de Néstor Pedro Sagüés (2007), "importa, en verdad, una clase o especificación del derecho de intimidad" (p. 692). Y, en este caso, la tutela puede estar referida al pensamiento mismo mediante la prohibición de interferencia estatal, quedando imposibilitado el Estado de llevar adelante coercitivamente acciones tendientes al adoctrinamiento compulsivo, o la imposibilidad estatal de realizar un escrutinio sobre la validez o bondad del mismo. Entiendo que es esta la posición correcta y que, además, es la posición adoptada por nuestra Corte Suprema que en reiteradas oportunidades ha manifestado la improcedencia de que el Estado realice una valoración sobre el pensamiento o creencias de una persona.

Más allá de estas observaciones, si bien la libertad de pensamiento no tiene tutela de manera expresa en el texto constitucional, la Corte Suprema de Justicia la ha reconocido, aunque sin desarrollarla, en "Ponzetti de Balbín" (CSJN, 1984, Fallos 306:1892) al sostener que la libertad de prensa es una manifestación política de la libertad de pensamiento.

Por su parte, la libertad de conciencia, que tampoco encuentra reconocimiento constitucional expreso, supone la libertad "de creer en lo que se desee, sea en materia política, social, filosófica o religiosa. Involucra también, entonces, la libertad de creencias. La libertad de conciencia, en resumen, es una 
variante de la libertad de pensamiento" (Sagüés, 2007, p. 723). Su distinción con la libertad de culto ha sido dada por la Corte Suprema de Justicia en el ya mencionado caso "Portillo" (CSJN, 1989, Fallos 312:496), donde sostuvo que

El ámbito de posible violencia estatal al fuero interno abarca el sistema de valores no necesariamente religiosos en los que el sujeto basa su propio proyecto de vida. Una interpretación diferente, nos llevaría al contrasentido de proteger el derecho a la libertad de cultos, como una forma de exteriorización del derecho a la libertad de conciencia, y no a atender a este último como objeto de protección en sí mismo (considerando $9^{\circ}$ ).

No es esta, nuevamente, la posición de autores como Horacio Rosatti (2017) al sostener que "la creencia religiosa forma parte de la libertad de conciencia y es irrelevante para el derecho; el ejercicio del culto es jurídicamente relevante y puede ser reglamentado y/o prohibido" (p. 455). Reitero las consideraciones hechas al tratar la libertad de pensamiento.

Más allá de las distinciones conceptuales, lo que es meridianamente claro, es que si bien la libertad de conciencia y la libertad de culto poseen un ámbito de tutela autónoma el uno del otro, existe una evidente vinculación.

Es por ello que la libertad de conciencia ha sido extraída pretorianamente del artículo 14 de la Constitución Nacional, en tanto garantiza que todos los habitantes de la Nación gozan del derecho de profesar libremente su culto, y como zona de autonomía personal donde el Estado no puede interferir, en virtud del artículo 19 de la Constitución Nacional; además esta vinculación se ve claramente en tanto que los instrumentos internacionales de derechos humanos, todos con más o menos los mismos términos, hacen un tratamiento conjunto de ambas. Así, el artículo 18 de la Declaración Universal de Derechos Humanos, el artículo 18 del Pacto Internacional de Derechos Civiles y Políticos, el artículo III de la Declaración Americana de Derechos y Deberes 
del Hombre, y el artículo 12 de la Convención Americana sobre Derechos Humanos.

En el orden interno argentino, entonces, el artículo 14 de la Constitución Nacional garantiza a todos los habitantes el derecho de ejercer libremente su culto. Ya fue señalado, siguiendo a Gullco (2016), que esta libertad abarca no solo la profesión de la religiosidad sino, además, de las conductas derivadas de motivos éticos, morales o filosóficos.

La libertad de cultos comporta, a su vez, una doble dimensión, en tanto supone una dimensión interna relativa a la formación, mantenimiento, cambio e incluso abandono de las propias convicciones; y una dimensión externa que se relaciona con el derecho a actuar sobre el mundo conforme a tales convicciones. La primera dimensión, por formar parte del fuero íntimo de cada persona, se encuentra tutelada por el principio de autonomía personal del artículo 19 de la Constitución Nacional. La segunda dimensión, en cambio, es la expresamente tutelada por el artículo 14 de la Constitución Nacional. Es válido aclarar, por lo demás, que la exteriorización no se agota en los actos rituales solemnes de veneración o pertenencia a determinado culto, sino que además puede manifestarse con abstenciones, silencios o reacciones frente a un estímulo determinado (Rosatti, 2017).

A su turno, el Sistema Interamericano de protección de derechos humanos, en especial el artículo III de la Declaración Americana de Derechos y Deberes del Hombre y el artículo 12 de la Convención Americana sobre Derechos Humanos, delimitan el alcance y el contenido de la libertad cultos con seis prerrogativas específicas:

1) profesar una religión, es decir, tener una creencia religiosa; 2) manifestar una creencia en público o en privado, de forma individual o colectiva, esto es, dar a conocer o exteriorizar la religión que se profesa; 3) practicar los preceptos de una determinada religión en público o en privado de forma individual o colectiva, en otras palabras, llevar a cabo o realizar las convicciones religiosas; 4) conservar una religión o mantener la creencia; 5) cambiar 
de religión, lo que significa tener la posibilidad de dejar una religión y tomar otra, y 6) difundir una religión, lo que implicaría transmitir las creencias religiosas a otros (Romero Pérez, 2012, p. 219)

Asimismo, estos instrumentos internacionales disponen límites al actuar estatal en torno a la protección de la libertad religiosa. Así, si bien los Estados parte de la Convención Americana sobre Derechos Humanos pueden restringir la libertad religiosa mediante leyes, la restricción solo pasará el tamiz convencional si es necesaria para proteger la seguridad, el orden, la salud o la moral públicas, o el derecho o libertades de los demás. Tampoco pueden los Estados imponer una religión a los menores de edad, donde queda reservado a los padres o tutores el derecho de elegir la educación religiosa o moral para sus hijos o pupilos, de acuerdo a sus propias convicciones. Y por último, se desprende del artículo 27 de la Convención Americana, que ningún Estado puede suspender la garantía de la libertad religiosa bajo ninguna circunstancia.

Por su parte, en el sistema universal de protección de derechos humanos, con particular referencia a la Declaración Universal de los Derechos Humanos y al Pacto Internacional de Derechos Civiles y Políticos, se sostiene la misma tesitura al reconocer que esta libertad es de contenido tanto teísta como no teísta, e incluso atea, y que supone las mismas prerrogativas y los mismos límites que ya hemos referido para el sistema interamericano.

Ahora bien, realizadas estas conceptualizaciones y determinada la fuente normativa de cada una de las libertades en juego, la objeción de conciencia se presenta en nuestro ordenamiento de manera derivada y no autónoma. Su fuente normativa, entonces, sería la misma que las de estas libertades ya que, en su construcción derivada, siempre se encuentra referida a alguna de ellas.

Este proceso de reconocimiento de la objeción de conciencia a través de la jurisprudencia de la Corte Suprema de Justicia de la Nación, es el que se desarrolla a continuación. 


\section{El camino trazado: la conceptualización de la objeción de conciencia en la jurisprudencia de la Corte Suprema de Justicia de la Nación}

Ya fue puesto de relieve que, a lo largo de su historia, la Corte Suprema de Justicia de la Nación se ha expedido en varios pocos casos en que abordó directamente la cuestión relativa a la objeción de conciencia y, en otros, donde las referencias a la misma se realizan con carácter secundario o bien las cuestiones planteadas fueron resueltas con referencia a otros valores jurídicos en juego. De todos ellos, sin embargo, no se obtiene una jurisprudencia profusa ni abundante, pero sí se desprenden importantes conceptos doctrinales que permiten desarrollar el instituto, al menos, como punto de partida para su profundización. Asimismo, resulta claro que la caracterización doctrinaria de la propia Corte Suprema fue mutando al respecto.

En este sentido, cabe mencionar como antecedentes destacados los casos "Agüero" (CSJN, 1949, Fallos 214:139) sobre la necesidad de juramentar para la validez de ciertos actos públicos; "Lopardo" (CSJN, 1982, Fallos 304:1524) y "Falcón" (CSJN, 1983, Fallos 305:809) en referencia a la posibilidad de eximición de la prestación del servicio militar obligatorio; "Ascencio" (CSJN, 1982, Fallos 304:1293) respecto de la reverencia a símbolos patrios; entre otros, y cuyo estudio se omite en el presente trabajo en razón a la brevedad del mismo.

Hasta aquel momento, la Corte Suprema de Justicia de la Nación se mostró reaccionaria al reconocimiento de la objeción de conciencia como causal justificada de insumisión al derecho. El giro jurisprudencial más importante llegaría de la mano del fallo "Portilo" (CSJN, 1989, Fallos: 312:496). En este caso, por primera vez, la Corte Suprema va a reconocer rango constitucional a la objeción de conciencia.

En los hechos, Alfredo Portillo, de religión católica, consideraba que el servicio militar obligatorio colisionaba con el quinto mandamiento de no matar. Al no presentarse a prestar el servicio, fue condenado en primera instancia a prestar un año 
de servicios continuados en las Fuerzas Armadas, más el tiempo legal que le hubiera correspondido. Ante la Corte Suprema de Justicia de la Nación, el actor se agravió, en primer lugar, de que la incorporación compulsiva al servicio dispuesto la Ley 17.531, violaba su libertad personal consagrada en el artículo 14 de la Constitución Nacional. En particular su libertad ideológica y de conciencia. En segundo lugar, consideró que podía servir a la Patria con un medio alternativo de carácter civil, como prestación sustitutoria, que no implicara empuñar armas.

La Corte Suprema reconoció la existencia de una tensión entre dos disposiciones de carácter constitucional. Por un lado, los derechos de libertad derivados del artículo 14, en particular el derecho de libertad de culto, y, por el otro, la obligación de armarse en defensa de la patria y la Constitución establecida en el artículo 21 y en el preámbulo constitucional.

Al realizar el escrutinio de razonabilidad, la mayoría de la Corte entendió que, si bien por el deber inherente al título de ciudadano - deber de armarse en defensa de la Patria y de la Constitución- las leyes pueden exigirle los servicios que derivan de tan expresa obligación, donde claramente se inscribía la ley $\mathrm{N}^{\circ} 17.531$, ese deber no deja de ser de naturaleza relativa (considerando $5^{\circ}$ ). Por lo tanto "El deber - relativo- proveniente de la necesidad de armarse en defensa de la Patria y de la Constitución, y la libertad religiosa — también relativa- no necesariamente resultan inconciliables" (considerando $12^{\circ}$ ).

La Corte va a considerar ambos valores en juego y, respecto de la obligación impuesta por el artículo 21 de la Constitución Nacional, dirá que el servicio de conscripción ha sido estructurado en vistas a una alta finalidad, la cual es hacer material y efectivamente posible la preparación para la defensa de la Nación, en tiempo de paz, mediante el adiestramiento militar de sus hijos (considerando $5^{\circ}$ ). Por su parte, también resaltará que la libertad de religión es particularmente valiosa para la humanidad y que, para el hombre religioso, la misma es el elemento fundamental de la concepción que se forma del mundo que, en 
mayor o menor medida, va a impregnar todos los actos de su vida individual (considerando $8^{\circ}$ ).

Para la conciliación de estos dos valores jurídicos contrapuestos, ambos de raigambre constitucional, postuló que

La reglamentación legislativa de las disposiciones constitucionales debe ser razonable, esto es, justificada por los hechos y las circunstancias que les han dado origen y por la necesidad de salvaguardar el interés público comprometido y proporcionado a los fines que se procura alcanzar, de tal modo de coordinar el interés privado con el público y los derechos individuales con el de la sociedad (considerando $7^{\circ}$ ).

Y así, luego de propuesto el test de razonabilidad para la resolución del conflicto, arribó a la solución de que el incumplimiento del deber constitucional en los términos de la ley del servicio militar obligatorio, en tiempos de paz, no conllevaba un peligro grave o inminente a los intereses del Estado, debiéndose explorar alternativas que permitan cumplir el mandato sin violentar las convicciones morales del agente. Esto es, una prestación sustitutoria que, en el caso, no implique la portación de armas.

Hasta aquí, la solución del caso transcurrió por los carriles de la libertad de conciencia y la libertad de cultos. Ya en lo estrictamente relacionado a la objeción de conciencia, la Corte Suprema va a sostener - obiter dictum - que reflexiones como las del caso son las que, probablemente, llevaron a otros países a legislar excepciones para los objetores de conciencia y a organismos internacionales a pronunciarse sobre el punto.

Asimismo sostuvo, respecto de quienes invoquen la objeción de conciencia como eximente del cumplimiento de un deber legal, que "parece necesario que quien lo invoque, haya de hacerlo con sinceridad" (considerando $13^{\circ}$ ), y en este sentido deberá demostrar que el cumplimiento de la obligación "le produce un serio conflicto con sus creencias religiosas o éticas" (considerando $13^{\circ}$ ). 
Por último, la Corte Suprema agregó que "no es desacertado sostener que la solución global de estos problemas pasa por la decisión del legislador, por cuanto es de su resorte la reglamentación general del artículo 21" (considerando 15), como así también lo será de todos aquellos casos donde los deberes impuestos a los ciudadanos puedan comprometer su conciencia. Pero aún ante la inexistencia de excepciones por motivos de conciencia en la norma, corresponde a los jueces hacer valer siempre los derechos individuales en los casos concretos (considerando $15^{\circ}$ ).

Por lo que resta, de los fundamentos del fallo parece desprenderse que la objeción de conciencia es, principalmente, una especificidad de la libertad de conciencia que, en el entendimiento de la Corte Suprema, merece reconocimiento y tutela autónoma respecto de la libertad religiosa o de cultos. Sobre este punto se va a volver en las consideraciones finales.

Más clarificador al desarrollo de una teoría de la objeción de conciencia con carácter autónomo resulta, a mi criterio, el voto de los jueces Mariano Augusto Cavagna Martínez y Antonio Boggiano en el caso "Bahamondez" (CSJN, 1993, Fallos 316:479), donde se planteó la cuestión relativa a los límites estatales frente a los tratamientos médicos.

En el caso, Marcelo Bahamondez, perteneciente a la religión Testigos de Jehová, se encontraba internado en un hospital de la ciudad de Ushuaia a raíz de una hemorragia digestiva. El paciente se negó a recibir transfusiones sanguíneas por considerar que ello contravenía sus más íntimas creencias, derivadas de su práctica religiosa.

Al momento de decidir la Corte Suprema el caso se encontraba abstracto pues, en el lapso de cuatro años transcurridos hasta la intervención del tribunal, el paciente se había recuperado y había sido dado de alta médica sin necesidad de haber realizado las transfusiones sanguíneas.

A pesar de la situación procesal, algunos de los ministros de la Corte Suprema se expidieron respecto del fondo del asunto para que, en el futuro, los casos similares que requerían solución 
urgente conocieran la posición de algunos magistrados del máximo tribunal nacional.

Dentro de los distintos votos, se reflejan dos claras líneas interpretativas. Por un lado, el encuadramiento del caso como un supuesto típico de objeción de conciencia y libertad religiosa, a instancias del voto de los ya mencionados jueces Cavagna Martínez y Boggiano y, por otro lado, una línea que vincula al caso a la esfera de privacidad consagrada en el artículo 19 de la Constitución Nacional, lo que ocurre a través del voto de los jueces Belluscio y Petracchi.

Esta segunda línea interpretativa del caso, de mayor amplitud, tiene la ventaja de poder proyectarse a casos cuyo encuadre no se de en los términos exclusivos de la objeción de conciencia. Criterio que en definitiva se cristaliza sobre la base de que el ámbito de libertad reconocido a las personas en el artículo 19 de la Constitución Nacional, se proyecta también en el derecho y la posibilidad de que cada uno pueda aceptar o rechazar libremente toda interferencia, también, en el ámbito de su intimidad corporal.

Por su parte, en torno a la primera línea interpretativa, que resulta de mayor interés para este trabajo, la objeción de conciencia fue definida como "el derecho a no cumplir una norma y orden de la autoridad que violente las convicciones internas de una persona, siempre que dicho incumplimiento no afecte significativamente los derechos de terceros ni otros aspectos del bien común" (considerando $12^{\circ}$ ).

En este sentido, la objeción de conciencia se presenta como un incumplimiento individual de una obligación jurídica positivizada. $\mathrm{O}$, como también fue sostenido al brindar un marco teórico a este trabajo, el incumplimiento de un mandato legislativo o de una orden administrativa. Incumplimiento que se va a pretender justificado en tanto el mandato violente las convicciones personales del agente que esquiva el deber legal.

Es decir que el incumplimiento va a tener como principal fundamento que, de actuarse conforme al precepto legal, se 
lesiona al individuo obligado en sus creencias y convicciones más íntimas, sean estas creencias de carácter ético, religioso, moral o filosófico, ya que "la libertad conciencia consiste en no ser obligado a un acto prohibido por la propia conciencia, sea que la prohibición obedezca a creencias religiosas o a convicciones morales" (considerando $8^{\circ}$ ). Esta amplitud de motivos a los que el objetor puede apelar para justificar su desobediencia, también es coincidente con la teoría rawlsiana.

Ahora bien, harto reiterado, "la libertad de conciencia, en su ejercicio, halla su límite en las exigencias razonables del justo orden público" (considerando $12^{\circ}$ ) y, en el caso, "si no se hallan afectados los derechos de otra persona distinta de quien se negó a recibir una transfusión sanguínea, mal puede obligarse a éste a actuar contra los mandatos de su conciencia religiosa"(considerando $17^{\circ}$ ).

Pero además, se va a requerir que el objetor sea sincero y serio en su accionar, y que el incumplimiento se enmarque en una coherencia de vida respecto a las convicciones que se alegan, por eso "quien invoca la objeción de conciencia debe acreditar la sinceridad y seriedad de sus creencias, verbigracia, la pertenencia al culto que se dice profesar" (considerando $12^{\circ}$ ). En especial, sostiene el voto, se deberá tener en cuenta la conducta anterior del objetor.

A diferencia de "Portillo", aquí la objeción de conciencia encuentra su fundamento, a criterio del voto disidente, en la libertad religiosa como ejercicio de la libertad de conciencia y no ya como una especificidad de una tutela autónoma de ésta. También sobre este punto se volverá hacia el final.

Lo que además resulta valioso del voto comentado es que "resulta irrelevante la ausencia de una norma expresa aplicable al caso que prevea el derecho a la objeción de conciencia" (considerando $19^{\circ}$ ) ya que "está implícito en el concepto mismo de persona, sobre el cual se asienta todo el ordenamiento jurídico" (considerando $19^{\circ}$ ), lo que permite afirmar "la tutela constitucional de la objeción de conciencia con apoyo en los artículos 14 y 33 de la Constitución" (considerando $19^{\circ}$ ). 
En otro caso trascendente, en el año 2012, la Corte Suprema de Justicia de la Nación se expidió en la causa "Albarracini Nieves" (CSJN, 2012, 335:799), en el que mantuvo su posición respecto del precedente "Bahamondez" sobre libertad, autonomía individual y objeción de conciencia.

En cuanto a los hechos del caso, el paciente Pablo Albarracini Ottonelli, que se encontraba internado en estado crítico en una clínica de la Capital Federal, requería para su tratamiento la realización de transfusiones sanguíneas. En este caso, la objeción de conciencia del interesado es invocada por su esposa, ya que él se encontraba en estado de inconsciencia, manifestando ella que el paciente era Testigo de Jehová y que, por lo tanto, se había negado a recibir tratamientos que implicaran transfusiones de sangre.

Como prueba de lo sostenido, la esposa de Pablo Albarracini Ottonelli acompañó un documento firmado ante escribano público, donde expresaba tal voluntad de manera clara y precisa.

Aquí, la Corte Suprema de Justicia de la Nación va a decidir también por la tutela de los derechos individuales. Así, los ministros Fayt y Petracchi, remitieron a sus propios fundamentos en "Bahamondez", en tanto que el resto de los jueces de la Corte Suprema adoptaron la línea del blindaje a la esfera de privacidad del artículo 19 de la Constitución Nacional que, como explicamos, es más amplia que la especificidad de la objeción de conciencia, a la que no excluye.

Puede decirse de este fallo que, como novedad, la Corte Suprema toma para sí el razonamiento del Tribunal Europeo de Derechos Humanos en "Case of Jehova's witnesses of Moscow and others v. Russia", al sostener que

"la Corte Europea de Derechos Humanos ha recordado en este sentido que 'prima facie, cada adulto tiene el derecho y la capacidad de decidir si acepta o no tratamiento médico, aun cuando su rechazo pueda causar daños permanentes a su salud o llevarlos una muerte prematura. 
Mas aún, no importa si las razones para el rechazo son racionales o irracionales, desconocidas o aún inexistentes" (considerando $17^{\circ}$ ).

Así trazado el camino de la Corte Suprema de Justicia de la Nación en el reconocimiento de la objeción de conciencia, aunque de manera derivada y no autónoma, nos permite extraer importantes consideraciones respecto de este instituto en nuestro ordenamiento jurídico, que se desarrollarán oportunamente.

\section{Consideraciones finales}

Es innegable que la objeción de conciencia, en la actualidad, es uno de los grandes temas jurídicos a desarrollar en el Siglo XXI, en atención a la rápida expansión en cuanto a sus ámbitos de manifestación.

Sin embargo, como se ha puesto de manifiesto a lo largo del presente trabajo, la objeción de conciencia no goza en nuestro ordenamiento jurídico de una tutela expresa ni, tampoco, de un reconocimiento como un derecho autónomo, sino derivado de las libertades de pensamiento, de conciencia y de religión, en un juego armónico con el principio de autonomía individual.

Este reconocimiento, surgido en base a las previsiones de los artículos 14 y 19 de la Constitución Nacional y de los instrumentos internacionales de derechos humanos que conforman el bloque de constitucionalidad federal, es producto de la construcción que a lo largo de la historia ha realizado la Corte Suprema de Justicia de la Nación.

Si bien es cierto que la mayoría de las veces en las que se han presentado casos donde la objeción de conciencia podía desarrollarse, el tribunal rara vez ha optado por resolverlos a través este instituto y, ello, hace que la jurisprudencia en nuestro medio sea escasa.

Por mi parte, tomando como autor de referencia a John Rawls en su "Teoría de la Justicia", entiendo y creo conveniente que la objeción de conciencia sea reconocida, desarrollada 
y legislada como un instituto jurídico autónomo, con pautas generales para su aplicación para todos los casos en que ella sea susceptible de ser invocada por quien se niega al cumplimiento de una obligación que se encuentra positivizada.

La posibilidad de insumisión al derecho por razones religiosas, éticas, morales o filosóficas, puede y debe ser seriamente atendida. El Estado Constitucional y Democrático exige, en tiempos de pluriculturalidad y globalización, que se adopten medidas tendientes a garantizar la convivencia pacífica y, en este sentido, como sostienen María Carmelina Londoño Lázaro y Juana Inés Acosta López (2016) resulta evidente que la objeción por razones de conciencia cumple una clara función conciliadora, facilitando la vigencia armónica de los derechos humanos (p. 236).

Por todo ello es que resultará necesario, y más temprano que tarde, el avance del legislador en la materia y el desarrollo del instituto con carácter autónomo. Lo propio deberá ser hecho en los ámbitos académicos $\mathrm{y}$, por tal motivo, este trabajo forma parte de la tesis de maestría que me encuentro desarrollando.

\section{Bibliografía}

ALEGRE, M. (2009). ¿Opresión a conciencia?: La objeción de conciencia en la esfera de la salud sexual y reproductiva. Yale Law School SELA (Seminario en Latinoamérica de Teoría Constitucional y Política) Papers. Paper 66. Recuperado de https:// digitalcommons.law.yale.edu/yls_sela/66

GULLCO, H. (2016). Libertad religiosa. Ciudad Autónoma de Buenos Aires, Argentina. Ediciones Didot.

SARLO, Ó. (2006). El marco teórico en la investigación dogmática. En Observar la ley: ensayos sobre metodología de la investigación jurídica. Madrid, España: Trotta.

RAWLS, J. (2012). Teoría de la justicia. México D.F., México: Fondo de Cultura Económica.

GASCÓN ABELLÁN, M. (1990). Obediencia al derecho y objeción de conciencia. Madrid, España: Centro de Estudios Constitucionales. 
ARLETAZZ, F. (2012). Libertad religiosa y objeción de conciencia en el derecho constitucional argentino. En Estudios constitucionales. Santiago de Chile, Chile: Centro de Estudios Constitucionales de Chile Universidad de Talca.

ROSATTI, H. (2017). Tratado de Derecho Constitucional. Santa Fe, Argentina: Rubinzal-Culzoni Editores.

SAGÜÉS, N. (2007). Manual de Derecho Constitucional. Ciudad Autónoma de Buenos Aires, Argentina: Editorial Astrea.

ROMERO PÉREZ, X. (2012). La libertad religiosa en el Sistema Interamericano de Protección de los Derechos Humanos (Análisis comparativo con el ordenamiento jurídico colombiano). En Revista Derecho del Estado. Bogotá, Colombia: Universidad Externado de Colombia.

LODOÑO LÁZARO, M. \& ACOSTA LÓPEZ, J. (2015). La protección internacional de la objeción de conciencia: análisis comparado entre sistemas de derechos humanos y perspectivas en el sistema interamericano. ACDI - Anuario Colombiano de Derecho Internacional, 9, 233-272. doi:http://dx.doi.org/10.12804/ acdi9.1.2016.07

\section{Jurisprudencia}

Portillo, Alfredo s/ infr. art. 44 ley 17.531 (1989). Corte Suprema de Justicia de la Nación. Tomo: 312 Número: 496.

Ponzetti de Balbín, Indalia c/Editorial Atlántida S.A. (1984). Corte Suprema de Justicia de la Nación. Tomo: 306 Número: 1892. Agüero, Carlos Antonio c/ Universidad Nacional de Córdoba (1949) Corte Suprema de Justicia de la Nación. Tomo: 214 Número:139.

Lopardo, Fernando Gabriel s/ insubordinación (1982). Corte Suprema de Justicia de la Nación. Tomo: 304 Número:1524.

Falcón, Javier Ignacio s/ insubordinación (1983). Corte Suprema de Justicia de la Nación. Tomo: 305 Número: 809.

Ascencio, José Hernán s/ amparo (1982). Corte Suprema de Justicia de la Nación. Tomo: 304 Número: 1293.

Bahamondez, Marcelo s/ medida cautelar (1993). Corte Suprema de Justicia de la Nación. Tomo: 316 Número: 479. 
Albarracini Nieves, Jorge Washington s/ medidas precautorias (2012). Corte Suprema de Justicia de la Nación. Tomo: 335 Número: 799.

\section{Otras}

Corte Interamericana de Derechos Humanos (1985). Colegiación Obligatoria de Periodistas (Artículos 13 y 29 Convención Americana Sobre Derechos Humanos). Opinión Consultiva OC-5/85. Recuperado de http://www.corteidh.or.cr/docs/ opiniones/seriea_05_esp.pdf. 